\title{
Culture, Family Planning and the Number of Children
}

\author{
TIMO LOVIO
}

Research Associate

The Population Research Institute

\section{Introduction}

Over the past few years, there has been a lively debate in Finland on the factors that affect the birth rate. One of the contributions to this debate, Hämäläinen's article entitled »What Children Mean to Their Parents: A Qualitative Approach» appeared in this yearbook in 1986. My purpose in the present article is to combine an anthropological and a demographic approach with the help of the concept of family planning, and in this way supplement the views that have already been presented.

\section{Cultural change}

Hämäläinen $(1986,43)$ notes that the choices made by people depend at least in part on the surrounding culture. However, at the same time people react actively to this culture. This is also the case in connection with the questions of whether or not to have children and how many children each family (or each woman) should have. Hämäläinen is of the view that culture is reflected in human interaction and that symbols are a central facilitator of human communication. In itself, such thinking suggests that human societies have sought to regulate their size ever since people have existed (Himes, 1963).

The appropriateness of whom to marry and at what age to have children has been affected by the provisions on marriage. The production of the modern condom did not begin until the invention of the vulcanization of rubber in 1843-1844. However, the condom had existed for centuries before this (Himes, 1963, 187). Written prescriptions related to birth control date back thousands of years (Himes, 1963, 111). For this reason it cannot be said that only modern contraceptives have given people the possibility of deciding when to have children (Hämäläinen, 1986, 43).

In this study, Hämäläinen analyzes the psychological significance of children within a certain society and during a certain period as if he assumed that the psychological (for Hämäläinen, emotional) significance of children to their parents would always be the same. In fact, when speaking about children and their significance to their parents, there is reason to take the age of the children into consideration. In societies where the death rate during early and middle infancy (up to the age of five years) is high, the affective relation between young children and their parents differs from the corresponding relationship in a society where the death rate for children of this age is almost zero. In the latter case, there is no conflict in forming an emotional attachment with the expected child already during pregnancy or immediately after birth. 
One should also consider the age of children in the sense that the significance of small children to their parents differs from that of those in their youth. One should also take into consideration the significance of the structure of the family and of the economic and social structure of society.

The central significance of the family (by which Hämäläinen means the central position of the nuclear family) is not a natural phenomenon. Instead, the difference in family structures is a cultural manifestation that depends on the time and place, and for this reason varies constantly. It is important to note this because otherwise we would be mislead into adopting views of lifestyles that would unnecessarily result in cultural (learned) bias and conflicts where the cultural explanatory basis for the subject at issue would be false. Similarly, these views would be schematic and thus contrary to real life. If they were put into practice as societal policy, they would make life more difficult. By this, I am not suggesting that the nuclear family and monogamy would not continue to remain the most common alternative in Europe in the near future. The independent position of the nuclear family in relation to the previous generation has received emphasis on the material level, not just in the selection of one's spouse.

Hämäläinen's comment $(1986,53)$ that people naturally and innately assign the children and the family a central position is unjustified. The people that he has interviewed have responded in accordance with their culture, not with their nature. Thus, instead of dividing the reasons that parents have given for having children into internal and instrumental reasons, Hämäläinen should have divided them into cultural and instrumental reasons. However, all the reasons that Hämäläinen listed for having children are individual and/or family-oriented. They can be realized already with one child, as is the case for example with »making oneself immortal» through one's children.

From the point of view of culture, having children signifies continuity. Considering children a natural part of the cycle of life is an indication that those who have children accept and hope that life and, through this, also culture will continue. Even culture can continue if the birth rate is low, but in this case the way of thinking is no longer individualist or family-oriented, but instead community-oriented (or collective). In practice, people are tied to this community orientation through the division of labor. The instrumental significance that children have for their parents is tied to the value system, social status, the social system, modes of support in family policy, and the age and health of children and parents.

It is important to define the concepts natural and culture so that they are not confused with one another. This is because it has been suggested that culture regulates the birth rate as a whole. $»$ During the $1800 \mathrm{~s}$, cultural factors and the acceptance of the idea of birth control have apparently been more important than the economic and societal circumstances. These cultural factors have presumably been connected with changes in the traditional way of thinking, for example with the political radicalization and secularization that were typical of both Catholic and Protestant Europe» (Valkonen, 1982, 42). If the death rate had not decreased in all age groups, the population would scarcely have accepted family planning, which the population saw as a factor in decreasing child mortality and in this way bringing about a considerable improvement in the position of mothers (and fathers).

It is important to note that family planning, from the point of view of sciences other than demography, refers more to, and focuses on, the welfare of the family. Women raised the same number of children to adulthood with considerably fewer pregnancies. Nursing and other forms of child care that contributed to the lowering of the mortality rate would quite presumably have spread much more slowly if at 
all without the establishment of a system of general education, as it was this that contributed to the new spread of knowledge. What, then, is culture, if the lowering of the birth rate was specifically brought about by cultural change?

\section{Culture, continuity and education}

In anthropology as well as other sciences of man, the concept of culture is defined in different ways. One of these conceptualizations only considers the norms and values prevailing among the population of a certain area or of a certain ethnic group as »culture». However, such a concept of culture is too narrow; if used, the researcher would easily create ideal societies where the true internal conflicts among human societies (for example in the sectors of economics, politics and administration) may be hidden by the researcher's perhaps quite unjustified line of reasoning, and the image that develops would be one of a homogenous society with a feeling of solidarity, where the members live and carry out in harmony their collective way of life (culture) in their own »ecological niche».

The conceptualization of culture may also be one of day-to-day life activity, of which family planning is one example. In this, the focus of interest is on the ways in which the individuals or families decide on how many children they shall have. This is not possible except in public and private discussion. Thus, also this approach to the conceptualization of culture is connected with the understanding of culture as a »societal phenomenon» which exists in human interaction, in language (symbols). In respect of the question of having children, many sources of norms have taken part in this discussion on the number of children. It is to some extent unclear which source of norms or reference group has been critical for each person.

Even so, it is self-evident that along with the spread of the ability to read and write and, in general, along with the spread of communications, the local culture no longer serves as the reference group to the same extent as before. As a matter of fact, the circle of colleagues and friends serves as the reference group; society is organized according to the division of labor and to basic and vocational education, which is closely related to the division of labor. Thus, European societies which have become organized in this manner have customs traditions that are connected with professional groups and that also affect to some extent the number of children that is considered suitable per family.

From the point of view of family planning, the attempts to establish a welfare state began already during the previous century, along with the arrival of modern medicine.

If we consider the matter as outlined above, it proves to be quite difficult to influence fertility in an area unless we are able to justify this to the people in question. Indeed, we can note that during the present century Finland has moved from a country of separate societies to a strongly integrated society where, during the past few decades, no one society or ethnic group has carried out an expansive pronatal population policy.

The only natural feature of human reproduction is that men cannot become pregnant nor can they lactate. All other provisions, customs and usages that pertain to human reproduction and the care of children are part of culture and have been internalized along with the process of socialization. This is true also of the beliefs regarding the suitable number of children.

The introduction of general education during the previous century and the constant improvement since then of the channels of communication have resulted in a 
situation where the local culture no longer necessarily serves as the reference group that affects the number of children that people consider suitable. As a matter of fact, the number of marriages in Finland has constantly increased during the present century, up to the beginning of the 1950s. This has made it possible for families with many children to disappear without this leading to the end of the world.

Various ideals about the size of the family have interacted with one another. Consequently, the number of families with two and three children has constantly increased. At the beginning of the present century the decrease in the birth rate was most rapid in the southern part of the country. It quickly became more common to limit the number of children, in the cities more rapidly than in the countryside. It was not until the 1920 s that a considerable change took place in the countryside. There had not been any considerable differences between the cities in different countries in Finland in respect of the time at which the decrease in the birth rate began. On the other hand, there was such a difference in the rural areas. In the southernmost county in Finland, Uusimaa, the decrease in fertility could already be seen during the beginning of the 1910s, while elsewhere in southern Finland it began later during the 1910s. In the northernmost counties in the country (Kuopio, Vaasa and Oulu) fertility began to decrease during the 1920s (See Pitkänen, 1984, 18-19). In the cities, also the level of education was the highest.

The transfer of know-how from one generation to the next as a part of culture takes place in a society with a highly advanced division of labor. In this way, in schools the length of the basic education and the period of training for a vocation becomes a significant regulator of when it becomes possible for those reaching the age for the establishment of a family to have children. In this way, people can not arbitrarily have children if the normative structure of the society assigns the biological parents with the primary responsibility for their children. Thus, for example a lengthening of the period of education regulates how many children a person may have.

The only significance of modern contraceptives in this is that society no longer needs to regulate sexual behavior to the same extent as before. Thus in my view modern contraceptives primarily lessen the number of unhoped-for children, a fact which can also be seen in the systematic decrease in the number of abortions since 1973 (Ritamies, 1986). In the long run, they scarcely decrease over-all fertility to an essential extent; they only make life easier, as is suggested by Hämäläinen $(1986,43)$. It has been possible for people to have the children they want when they want them. In this way, it becomes possible to speed the transition from one stage in life to the next. Today, this is especially true of those who have received a low level of education.

The majority of those with a high level of education have great difficulties in adjusting the arrival of children to the demands of education and work. In this sense life has not become any easier. In a way, we can say that the decrease in the death rate has made it possible to lengthen the period of education and diversify it in order to match the increased division of labor brought about by know-how. Youth unemployment and the shortage of rental housing raise the age at which those who have received a shorter basic education and vocational training are ready to establish a family. These factors will ensure that the social structure will not permit the having of children at too young an age.

If we examine the lengthening of the period of basic education over the past few decades in Finland, we can note that no significant decrease in the average primiparous age can take place, nor is there necessarily a need for such a decrease.

The increase in the level of the basic education of the population can clearly be seen in Table 1. In particular the proportion of women who have graduated from secondary school is very high. A significant reform of the Finnish educational system 
took place during the 1970 s. The comprehensive school was introduced from 1972 to 1977 , and the system of academic degrees was reformed from 1977 to 1981 . The reform of the medium level of education took place at the beginning of the 1982 - 1983 semester in respect of upper secondary school. The reform of vocational education is being carried out from 1982 to 1988 (CSO 1984, 99). At least among secondary school graduates, there has been no increase in the speed with which there has been a move from completion of the basic education to an institution that would prepare one for a profession (CSO 1987b). This means in practice that no increase in fertility among those under 22 years of age is to be expected. Thus, quite evidently in the near future there will be a clearer concentration than before among those having children between the ages of 25 to 35 years old. One consequence of this is that there will scarcely be an increase in the number of families with several children. In 1985, $8 \%$ of those surviving birth were the fourth or higher child in the family (CSO 1987a, table 56,99$)$. This means in practice that in the future families will have between zero and three children, and the number of children born each year will depend on the spacing of the children and the relative proportion of families with different numbers of children. It is estimated that $10-15 \%$ of families have no children. Can it be that the desired number of children among young people at the age of fertility is so low that we can expect a lowering of total fertility to a problematic level?

$\mathrm{T}$ a b I e 1. The population according to sex and general basic education at the age of $20-24$, from 1950 to 1980 (and secondary school graduates from 1950 to 1985$)$.

Percentage $(\%)$ of the entire population in the $20-24$ year age bracket

\begin{tabular}{|c|c|c|c|c|c|c|c|c|c|}
\hline Sex & \multicolumn{4}{|c|}{$\begin{array}{l}\text { Completed lower secondary } \\
\text { or comprehensive school }\end{array}$} & \multicolumn{5}{|c|}{$\begin{array}{l}\text { Completed secondary } \\
\text { school }\end{array}$} \\
\hline & 1950 & 1960 & 1970 & 1980 & 1950 & 1960 & 1970 & 1980 & 1985 \\
\hline sexes & 7.4 & 12.0 & 17.9 & 34.0 & 4.9 & 8.5 & 16.3 & 29.0 & 37.1 \\
\hline & 5.4 & 8.9 & 14.7 & 35.0 & 4.5 & 7.4 & 13.5 & 22.4 & 27.9 \\
\hline men & 9.6 & 15.2 & 21.4 & 33.0 & 5.2 & 9.7 & 19.2 & 35.9 & 46.8 \\
\hline
\end{tabular}

(Source: OSF VI C: 106 VAL 80 Vol. VI A, 39, (preliminary data for 1985)

\section{Hopes regarding the number of children}

In this article, the hoped-for number of children has been estimated on the basis of data collected by a Finnish magazine directed at young families with children, "Kaks'Plus». The respondents are biased in favor of those who want four or more children. Furthermore, there are no unemployed or single parents among them. For this reason, the survey yields too low a figure for those favoring no children at all or one child. Even so, the survey provides a good opportunity to examine the question; the survey yielded 3500 respondents, and the 1000 first respondents were taken into consideration in the analysis of the data. It may be noted that there is no difference in the educational background and the amount of living space between the respondents and their spouses on one hand and the general population on the other. Also, the geographical distribution of the respondents corresponds to that of all families with children. The age distribution of the respondents was as follows: 
Age of respondents, in years

$\begin{array}{rrrrrr}17-24 & 25-29 & 30-34 & 35-39 & 40-46 & 47- \\ 20.8 \% & 42.0 \% & 27.4 \% & 7.5 \% & 2.0 \% & -\end{array}$

The questionnaire that was given to women respondents included the following question on the number of children desired: »How many children do you plan to have in your family?» The distribution of responses was as follows:

\begin{tabular}{|c|c|c|c|c|c|c|c|}
\hline None & 1 & 2 & 3 & 4 & $\begin{array}{l}5 \text { or } \\
\text { more }\end{array}$ & $\begin{array}{l}\text { Have not } \\
\text { given serious } \\
\text { thought to this }\end{array}$ & $\begin{array}{l}\text { Dependes } \\
\text { on how life } \\
\text { develops }\end{array}$ \\
\hline $0.2 \%$ & $2.6 \%$ & $24.7 \%$ & $30.9 \%$ & $10.8 \%$ & $2.4 \%$ & $4.2 \%$ & $24.1 \%$ \\
\hline
\end{tabular}

We should note, first of all, that in the sample the proportion of those not wanting any children or only one child is smaller than in reality. In the Finnish data for the World Fertility Study, as many as $11.3 \%$ considered one child to be the expected number in their family (Ritamies et al, 1984, 130). Because of the manner in which the sample was collected, only those who will have children responded to the study. Secondly, we should note that the proportion in the sample wanting five or more children corresponds to the true number among the entire population in the sense that in 1984-1985, 3\% of those surviving birth were the fifth or higher child in the family (CSO 1987a, 99). This would also indicate that their proportion of the final number of children in the family is not necessarily decreasing, even if it is not increasing; this is because among those who want so many children, the changes in the health of the mother and miscarriages generally mean that the actual number of children will be smaller than what had originally been planned.

Unfortunately, the question had been formulated so that those who wanted five children were grouped together with those who wanted even more. Earlier, I have attempted to show that, with some exceptions, it is not possible to establish such large families.

The number of families in the sample wanting four or more children corresponds to that found in the sample of the study mentioned earlier. If the same number of families that received their third child in 1984-1985 goes on to have a fourth child, the number of families in this sample that want four children would not be overly large. Although the past and past events cannot be used to predict what will happen, the number of hoped-for children shown by the study and their proportions out of all families corresponds so closely to the behavior of those who have entered into their first marriage that the results given by the sample appear to be reliable.

The sample yielded a significantly small proportion of women who stated that they had not given serious thought to the number of children that they wanted. This would indicate that family planning and the having of children as such have followed along with the other goals and motives that people have. Secondly, we should note that the proportion of respondents who stated that the total number of children would depend on how life develops would indicate that long-term demographic projections are quite unreliable. The issue depends to a large extent on what is decided in society.

On the other hand, this indicates that in fact people plan such matters in stages. Also the Finnish data for the World Fertility Study quite clearly give such indications (Ritamies et al, 1984). The result of this study was that $94 \%$ of women over 35 had had the children that they wanted, and that this decision also corresponded 
to their behavior. Also in the cases where they still intended to have children they knew how many additional children they wanted to have. In the study mentioned, the sample had been taken from among 19-to-45-year-olds in their first marriage. The data I myself have gathered is biased in that single parents and cohabiting couples are not represented. This means in practice that, since the results given by these two sets of data are so similar, the results yielded by my data are also reliable. Since the respondents in the sample were women, I consider the responses to provide a reliable predictor of what will happen in practice. We can therefore use various background factors in analyzing the relative proportions of the number of children hoped for.

If we consider the number of children that the respondents to our study stated that they wanted, on the basis of what has been said it is sensible to examine the relative proportions of the various alternatives by discarding those from the data who had not given serious consideration to the matter or who stated that the matter depends on how life develops. In doing this we assume that these respondents would in fact be distributed in the same way as those who specified the number of children that they wanted:

$\begin{array}{cccc}\begin{array}{c}\text { No children or } \\ \text { one child }\end{array} & 2 \text { children } & 3 \text { children } & \begin{array}{c}4 \text { or more } \\ \text { children }\end{array} \\ 4 \% & 35 \% & 43 \% & 19 \%\end{array}$

Such a distribution of the responses, with the discarding of the responses »have not given the matter serious thought» and "depends on how life develops» enlarges the proportion of those wanting four or more children to an excessive amount. For this reason, the estimates that shall be presented in the following overestimate the actual number of children in families. Even so, the result is quite clear, and we may note that among those who want children and can have them, the ideal number of children is concentrated around two and three. However, on the basis of earlier cohorts we can assume that some $10-20 \%$ will remain unmarried (or will not enter into cohabitation) or shall not have children. If we add these to the data in question, the proportions change as follows:

$\begin{array}{ccccc}\text { No children } & \text { One child } & 2 \text { children } & 3 \text { children } & \begin{array}{c}4 \text { or more } \\ \text { children }\end{array} \\ \% & \% & \% & \% & \% \\ 10 & 4 & 31 & 38 & 17 \\ 20 & 4 & 27 & 34 & 15\end{array}$

The above shows the significance of the size of the zero children alternative for the development. Its significance is increased even further by the fact that all signs indicate that in advance, people overestimate the number of children that they want, when compared with what they would estimate when they are older and have already had two or three children. Thus, the "four or more children» alternative has a tendency to decrease. This can be easily shown by dividing the respondents into four groups according to their age and place of residence, and then matching the families in accordance with the education factor.

Due to the lack of observations, the education factor has been made a bipartite one, where those who have attended vocational school and vocational courses form their own group (those with a »low» level of education), and secondary school graduates, students and those who have graduated from a technical college or university form another group (those with a "high» level of education) (Table 2). This is not quite consistent with the length of the period of education, as some move direct- 
$\mathrm{T} \mathrm{a} \mathrm{b} \mathrm{l} \mathrm{e} \mathrm{2.} \mathrm{Proportion} \mathrm{(} \%$ ) wanting various numbers of children by the size of the municipality, the age of the woman and the educational level of the parents. The table also shows the theoretical alternatives if $10 \%$ and $20 \%(\mathrm{a}=10 \%, \mathrm{~b}=20 \%)$ decide against having children or do not succeed in having children.

Population of municipality over 20000

Age of mother $30-46$ years $(n=137 / 1000)$

Desired number of children

0

1

2

3

4 or

more

Both parents have a

a $\begin{array}{rr}0 \\ 10\end{array}$

b 20

low level of education

Father has high level,

0

mother low level of

a 10

education

b 20

Mother has high level,

father low level of

0
10

education

b 20

Both have received a

high level of education

a $\begin{array}{rr}0 \\ \text { a }\end{array}$

b 20

All education groups

0

together

a 10

b 20

Population of municipality over 20000

Age of mother $17-29$ years $(n=203 / 1000)$

0

Desired number of children

Both parents have a

0

a 10

b 20

Father has high level, mother low level of

0
10

education

b 20

Mother has high level,

0

father low level of

a 10

education

b 20

Both have received a

high level of education

0

a 10

b 20

All education groups

0

together

a 10

b 20

1

2

3

4 or

more

10

10

46

12

10

41

35

10

9

25

22

15

20

13

10

44

39

34

9

8

30

27

11

10

24

9

37

33

29

13

12

10

Continued on next page 
Population of municipality under 20000

Age of mother $30-46$ years $(n=137 / 1000)$

Desired number of children

0

1

2

34 or

Both parents have a

$\begin{array}{rr} & 0 \\ \text { a } & 10 \\ \text { b } & 20\end{array}$

2

more

low level of education

0

Father has high level,

mother low level of

b 20

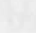

education

0

Mother has high level,

education

b 20

Both have received a

high level of education

$\begin{array}{lr} & 0 \\ \text { a } \quad 10\end{array}$

b 20

2

$23 \quad 43$

32

2

39

29

$18 \quad 35$

25

35

27

36

36

25

33

$\begin{array}{lll}29 & 21 & 29\end{array}$

anch level of education

0

All education groups

a 10

together

b 20

Population of municipality under 20000

Age of mother $17-29$ years $(n=213 / 1000)$

Desired number of children

0

1

2

3

4 or

more

Both parents have a

$\begin{array}{rr} & 0 \\ \text { a } & 10 \\ \text { b } & 20\end{array}$

39

19

low level of education

b 20

35

17

1

42

38

33

Father has high level, mother low level of

$\begin{array}{rr} & 0 \\ \text { a } \quad 10\end{array}$

education

b 20

30

15

Mother has high level,

Both have received a

high level of education

$\begin{array}{lr} & 0 \\ \text { a } & 10 \\ \text { b } & 20\end{array}$

All education groups together

ly to advanced education while others must try several times to get in. The same is true, of course, of finding a job and housing.

We may note that in municipalities with a population of over 20000 , the greatest change has taken place among those who have a lower of education. To be more specific, there was a decrease in those who wanted four or more children. However, it is true that, in an international perspective, even those who are classified here as having a low level of education in fact have completed an extensive basic education and, after this, various vocational courses of varying lengths. It would appear that, among those under the age of thirty, women with a low level of education and who are married to men with a high level of education shall have, or at least intend to 
have, the greatest number of children. It is true that the number of such women is decreasing, but it should be understood that those who are oriented towards their family and their children are to be found in this group. It should also be noted that the ideal number of children has increased among women with a high level of education who are married to men with a low level of education. Presumably this has been due, for example, to the improved maternity benefits, but an additional factor has been the change in the attitude of men towards child care, a change which at present can already be seen in participation in prenatal preparation and the actual delivery in hospital.

In small municipalities (less than 20000 in population) the trend of development has been the same even though the number desiring four or more children is somewhat larger (but at the same time considerably smaller than the corresponding figures for the older age group). In the smaller municipalities, one consequence of the flow of migration to the larger population centers has been more dwelling space per occupant and lower housing prices, and so in this respect the figures may be realized in fact. However, the basic trend in the ideal number of children has been from »three plus one extra» to three.

\section{Conclusions}

The birth rate in the near future depends to a considerable extent on the interval between the first and the second child. In 1971, 1975 and 1980 this interval ranged from 2.5 to 2.6 years (CSO 1984, 58). Since today a considerably greater proportion than in the 1960s want only two or three children, it is possible that the interval will increase. If this is the case, the annual number of births in the near future shall presumably remain as low as it is now.

A considerable proportion of the respondents stated that the final number of children in their family shall depend on how their life develops. To a large extent, this shall depend on societal and family policy. However, it is very difficult to use societal policy to intervene in the relationship between husband and wife, for example by preventing divorces.

Difficulties in combining one's working life and family life are usually greatest when the child is small, under three years of age. When such difficulties arise, the final number of children will be less than what had originally been hoped for. Ten percent of the respondents stated that they had difficulties in balancing the demands of their working life and family life. Only $41 \%$ stated that they had no such difficulties. $35 \%$ stated that the birth of the child had a surprising effect on their life. For only $13 \%$, the birth of the child had no such effect.

It can be assumed that the number of hoped-for children is greater than the number of children that the families shall actually have, in particular among those who want three or more children. For this reason, the number of children per family depends to a large extent on the proportion of families with no children or only one child. At the least, this is $10 \%$. However, it can also be $30 \%$ if, for example, it does not prove possible to obtain owner-occupied or rental housing at reasonable prices at the same time as youth unemployment is a problem in a great number of counties. It would appear that people want to find a job in their municipality of residence, and thus the amount of migration from one county to another shall remain low if societal policy is used in an attempt to prevent such migration.

The birth rate in Finland has been quite high in comparison with the other European countries. If one wishes an increase in fertility, this would only be possible if 
the flow of migration to the Helsinki metropolitan area can be slowed at the same time as housing policy tries to ensure that persons who were born and raised in other areas and who entering low-paying occupations are able to find affordable owneroccupied or long-term rental housing.

Quite obviously, the expectations among the population in respect of the amount of space each person should have has increased to such an extent that those who live in a one-room flat will not have any children and those who live in two-room flats will only have two children. The same applies to those who have short-term leases, since, because of their children, the parents become dependant on the availability of day-care facilities.

The structure of norms in our society places great emphasis on the significance of long-term care relationships for the balanced development of children, and conscientious parents seek to bear this in mind. Since families with one or two children think of what is good for the children, it is not necessarily a question of individualism or familism but specifically of the parents' society-oriented sense of responsibility. There are no reasons to assume on the basis of the data that the birth rate during the 1990 s shall be lower than during the 1980 s, but on the other hand it is difficult to imagine that the birth rate could increase beyond what it has been during the $1980 \mathrm{~s}$.

\section{References}

Henley, P. (1982). The Panare. Tradition and Change on the Amazonian Frontier. New Haven: Yale University Press.

Himes, N.E. (1963). Medical History of Contraception. New York: Gamut Press, Inc.

Honko, L.; and Pentikäinen, J. (1975). Kulttuuriantropologia (Cultural anthropology). Porvoo: WSOY.

Hämäläinen, J. (1986). What children mean to their parents. A qualitative approach. Yearbook of Population Research in Finland 24: 43-53.

Paasi, A. (1987). Kulttuurimaantieteen kehitys, sisältö ja kulttuurikonseptiot. (The development, contents and cultural conceptions of cultural geography). Suomen Antropologi 3: 136-146.

Pitkänen, K. (1984). The educated people: the precursors of the fertility transition in Finland. In: The Sixth Scandinavian Demographic Symposium, 16-19 June 1982 in Kungälv, Sweden. Studies in Fertility. Scandinavian Population Studies 6: 2, edited by the Forecasting Institute at Statistics Sweden, pp. 15-32. Stockholm: The Scandinavian Demographic Society.

Ritamies, M. (1986). Abortit meillä ja muualla. (Legal abortions in Finland and some other selected countries). Väestöntutkimuslaitoksen julkaisusarja D, nro 16. Helsinki: Väestöntutkimuslaitos.

Ritamies, M.; Riihinen, O.; Penttinen, H.; and Pulkkinen, A. (1984). Lapsilukuihanne - toive vai tavoite. (Ideal number of children - a wish or an aim). Väestöntutkimuslaitoksen julkaisusarja D, nro 13. Helsinki: Väestöntutkimuslaitos.

Sarmela, M. (1981). Suomalaiset häät (Finnish wedding ceremonies). In: Pohjolan häät, Tietolipas no 85, edited by Matti Sarmela, pp. 11-55. Helsinki: Suomalaisen kirjallisuuden seura.

CSO (Central Statistical Office of Finland) (1984). Suomalaisten elinolot. Living conditions in Finland. Statistical surveys no. 74. Helsinki.

CSO (Central Statistical Office of Finland) (1987a). Statistical Yearbook of Finland. Helsinki.

CSO (Central Statistical Office of Finland) (1987b). Uusien korkeakouluopiskelijoiden pohjakoulutus syyslukukaudella 1985. (The basic education of university students in autumn 1985). Tilastotiedotus KO 1987: 11. Koulutus ja tutkimus. Helsinki.

OSF (Official Statistics of Finland) (1983) Population and Housing Census 1980. Education; total population. VI C: 106. Volume VI A. Helsinki: Central Statistical Office of Finland.

OSF (Official Statistics of Finland) (1987). Population 1985. Structure of Population and Vital Statistics. Whole country and provinces. VI A: 151, Volume I. Helsinki: Central Statistical Office of Finland.

Valkonen, T. (1982). Väki lisaaäntyy vähemmän. (World population growth slowing down). Tiede 2000 (Helsinki) 5: 39-42. 